\title{
Reimplante dentario ulterior a su avulsión: reporte de caso clínico
}

\section{Reimplantation of the tooth after its avulsion: clinical case report}

\author{
Byron Morales"', Ma. Augusta Cordero ', Patricia Pinos ${ }^{1}$ \\ ${ }^{1}$ Docente de la carrera de odontología de la Universidad Católica de Cuenca. \\ *byronmorales@yahoo.com
}

DOI: https://doi.org/10.26871/killcanasalud.v5i1.821

\section{Resumen}

En el presente artículo, detallamos el caso clínico de un paciente de sexo femenino de 29 años de edad aproximadamente, que acude a la consulta para que se le realice un puente fijo en la zona de los dientes perdidos ya que su estética se vio afectada y no puede sonreír debido a que sufrió una caída como consecuencia de un ataque de epilepsia y se produjo la avulsión de las piezas dentarias 1.1 y 2.1 .

Durante la consulta la paciente comenta que luego del incidente fue atendida inmediatamente por un neurólogo y un cirujano máxilo facial porque presentaba heridas cortantes en el labio, y se le envió a la casa sin reimplantarle los dientes, y dio un dato relevante al mencionar que ella tiene los dientes en su casa guardados en suero fisiológico. Por lo que inmediatamente se solicitó traer los dientes y así cambiar el plan de tratamiento y proceder con el protocolo de reimplante.

A los ocho días de transcurrido el accidente se procede a realizar las endodoncias de los dientes avulsionados, y su posterior reimplantación en el alvéolo.

Palabras clave: avulsión, reimplante, endodoncia 


\section{Abstract}

Next, we detail the clinical case of a female patient of 29 years of age, who comes to the consultation to have a fixed bridge in the area of lost teeth since her aesthetic was affected and cannot smile because she suffered a fall as a result of an attack of epilepsy and there was avulsion of the dental pieces 1.1 and 2.1.

During the consultation, the patient commented that after the incident she was attended immediately by a neurologist and a maxillo facial surgeon because she had sharp cuts on her lip, and she was sent to the house without reimplanting her teeth, and she gave relevant information when mentioning that she has the teeth stored in physiological serum at home. We requested Immediately to bring the teeth and change the treatment plan and proceed with the reimplantation protocol.

Eight days after the accident, the endodontics of the avulsed teeth are carried out, and their subsequent reimplantation in the alveolus.

Keywords: Avulsion, reimplantation, endodontics 


\section{Introducción}

Las lesiones dentarias generalmente son provocadas por accidentes debido a golpes, traumatismos en donde se ven afectados dientes del sector anterior, ocasionando daños del ligamento periodontal del 15 al $61 \%$ de las lesiones orofaciales. A pesar de que sus efectos físicos son tratables y más importante aún, pueden prevenirse, sólo el $4 \%$ de los pacientes es atendido por un especialista en odontología. Así el 47\% de estos dientes reciben tratamiento, pero éste es inadecuado en el $59 \%$ de los casos. ${ }^{1-4}$

La avulsión dental es la expulsión de un diente fuera de su alveolo, causado generalmente por un traumatismo violento, provocando la subsecuente ruptura abrupta de las fibras periodontales y paquete vasculonervioso esto ocurre cuando el diente es desplazado. ${ }^{5-6}$

Cuando la avulsión afecta un diente anterior pueden producirse severas consecuencias psicológicas. ${ }^{7}$ el medio y las condiciones en las que se mantiene el diente avulsionado hasta el reimplante son básicos en el éxito o fracaso del tratamiento. Si la pieza dental tiene un tiempo extra oral inferior a 60 minutos se puede lograr una efectividad del procedimiento superior al $90 \%$ de los casos, no asi cuando el tiempo extraoral sobrepasa a 120 minutos. ${ }^{8,9}$ Se concluye que la premura en el cumplimiento y ejecución del protocolo a desarrollar son transcendentales para disminuir las probabilidades de fracaso o perdida de las piezas dentarias avulsionadas. ${ }^{10-11}$

En este caso clínico, el reimplante se realizó transcurridas 192 horas (8 días) y el diente permaneció en suero fisiológico, por lo que se le explico al paciente el posible fracaso del tratamiento por el tiempo transcurrido. Lo ideal para reimplantar un diente será alrededor de $15 \mathrm{a}$ 20 minutos, ya que, si no se mantiene en un medio adecuado, se producirá una necrosis de las células periodontales, así como de sus fibras periodontales.

Existen varias disyuntivas referentes a la conservación de los dientes avulsionados, como medios de conservación podemos mencionar la leche, ya que puede mantener al ligamento periodontal aproximadamente por 3 horas, otro medio es el suero fisiológico, la saliva no se recomienda ya que daña las células periodontales. ${ }^{12-13}$

\section{Presentación del Caso Clínico}

Paciente de sexo femenino de 29 años de edad, acude a la consulta ya que sufrió una caída como consecuencia de un ataque de epilepsia y se produjo la avulsión de las piezas dentarias 1.1 y 2.1 .

Fue atendida inmediatamente por un neurólogo y un cirujano máxilo facial porque presentaba heridas cortantes en el labio, y se le envió a la casa sin reimplantarle los dientes, los mismos que habían sido conservados en suero fisiológico. 
Transcurrido 8 días del accidente la paciente acude a la consulta y refiere el deseo de realizarse un puente fijo en la zona de los dientes perdidos, ya que su estética se ve afectada y no puede sonreír. Pero al saber que aún conservaba los dientes en suero fisiológico, se le dio la posibilidad de colocarle nuevamente sus propios dientes mediante la reimplantación de los mismos, es importante mencionar que es de suma importancia el espacio de tiempo que permanece los dientes fuera de su alvéolo antes del tratamiento, así como su mantenimiento en un medio adecuado.

En el análisis clínico oral se observa la avulsión de las piezas dentarias 1.1 y 2.1, corte desde el bermellón hasta el surco naso-mento-labial en la parte derecha cercana a la línea media facial.

Se elabora la propuesta del plan de tratamiento y se lo hace conocer al paciente.

A los ocho días de transcurrido el accidente se procede a realizar las endodoncias de los dientes avulsionados, y su posterior reimplantación en el alvéolo.

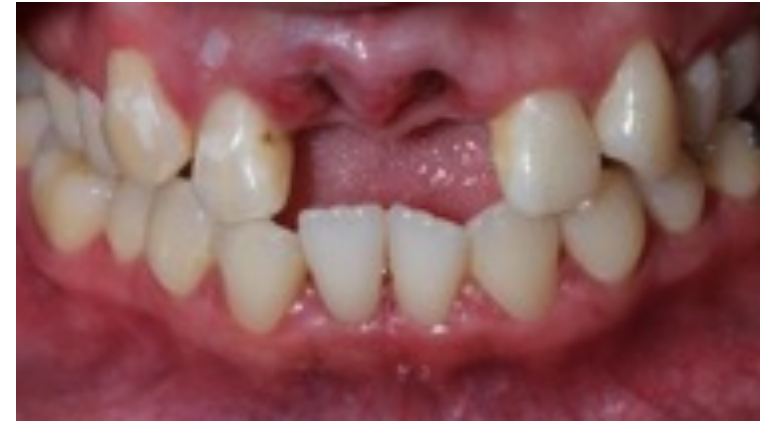

Figura 1.- Aspecto tras la avulsión de las piezas 1.1 y 2.1 ocho días después del incidente.

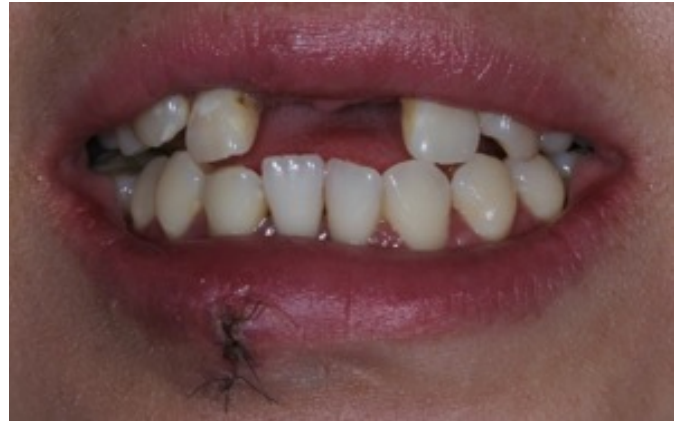

Figura 2.- Avulsión 1.1 y 2.1 Corte desde el bermellón hasta el surco naso-mento-labial

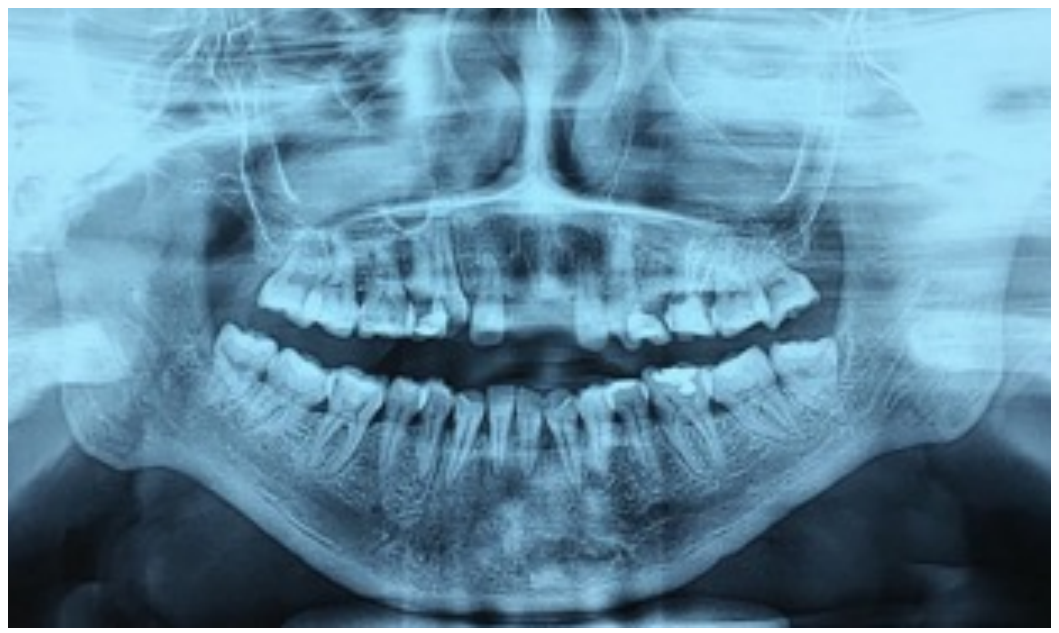

Figura 3.- Radiografía inicial 


\section{Ejecución del plan de tratamiento}

\section{Endodoncia de los dientes avulsionados}

Luego de haber receptado los dientes, se realiza el tratamiento de conducto de la pieza 1.1 y 2.1 con la técnica apico coronal y la obturación correspondiente con técnica de condensación lateral, se sella en la entrada del conducto con ionómero de vidrio y proceder al reimplante.

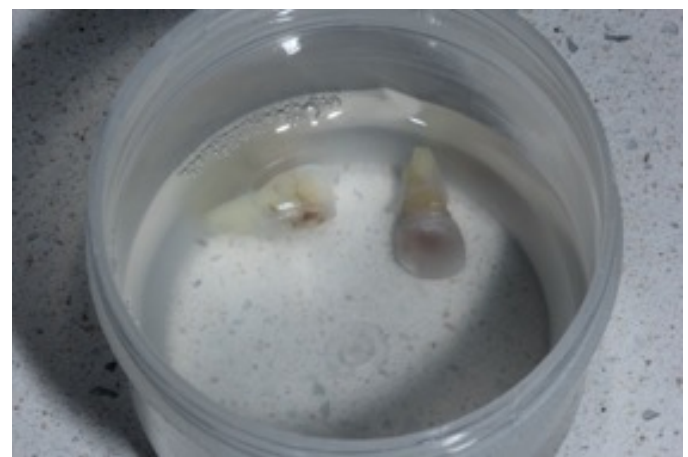

Figura 3.- Condición en la que llegan los dientes en suero fisiológico a los 8 días

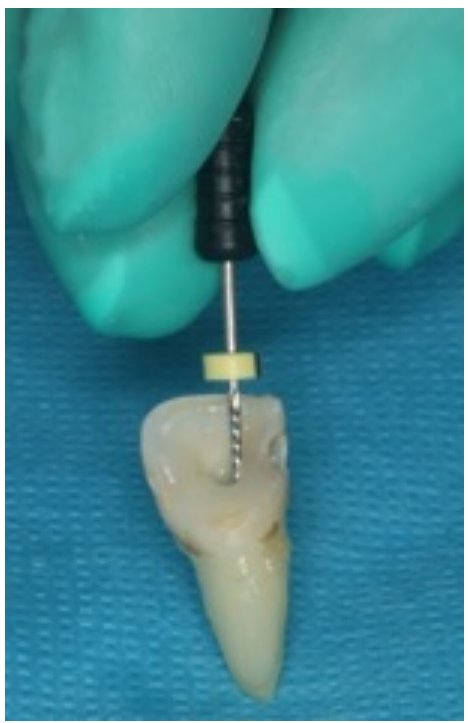

Figura 5.- Permeabilización e instrumentación del conducto extraoral

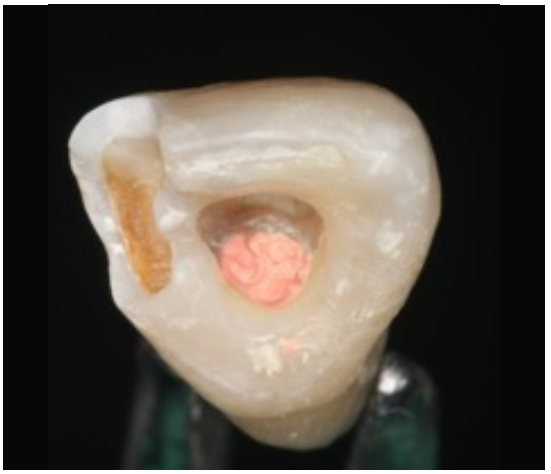

Figura 7.- Eliminación del exceso de cemento y gutapercha

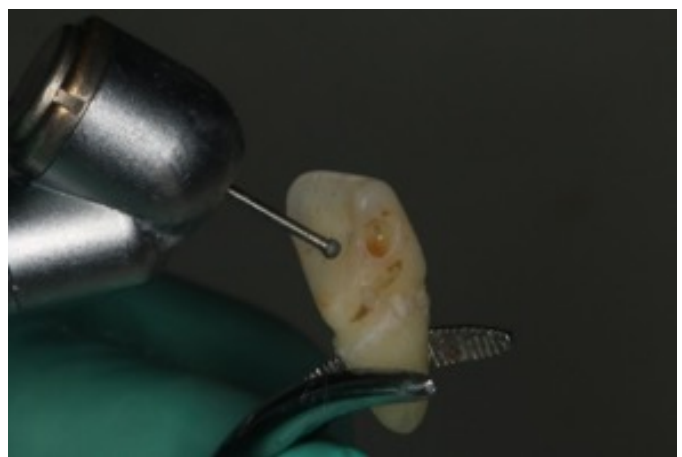

Figura 4.- Acceso coronario extraoral

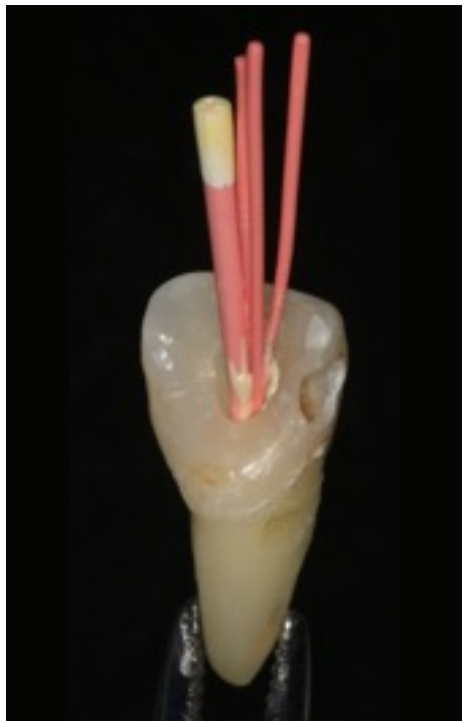

Figura 6.- Obturación radicular técnica de compactación lateral en frío extraoral

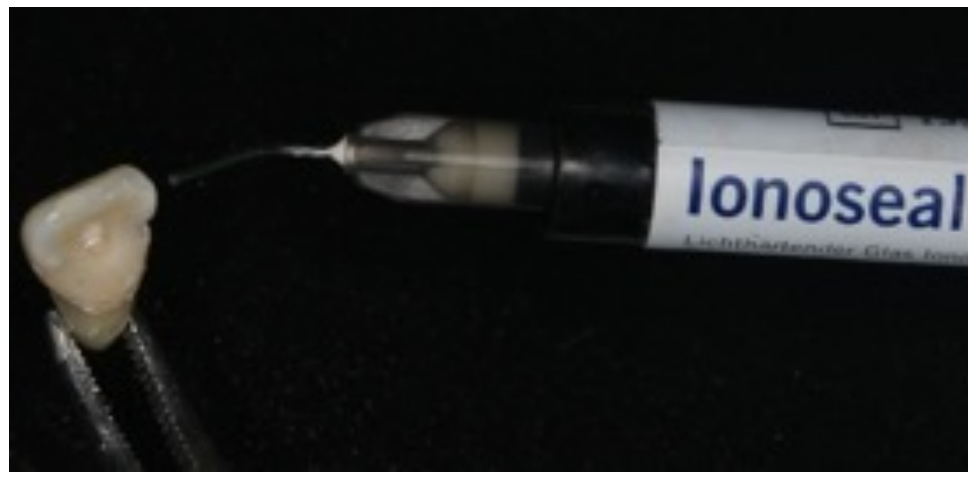

Figura 8.- Sellado coronal con ionómero de vidrio 


\section{Reimplantación}

Los incisivos se reimplantaron posterior a la preparación de los alveolos, sujetándolo suavemente por la corona, se suturaron los tejidos blandos con seda 3-0 y se procedió a realizar ligadura en 8 con alambre № 10, se realiza el grabado ácido por 20 seg con ácido fosfórico al $37 \%$, se lava el doble de tiempo, para eliminar cualquier residuo, se seca con chorro de aire a $1 \mathrm{~cm}$ de distancia por $5 \mathrm{seg}, 37$ y procedemos al bondeado y colocación de resina aufotopolimerizable Z100 de 3M.

Se prescribió terapia antibiótica durante siete días y se recomendó la protección antitetánica, insistiendo en la importancia de mantener la máxima higiene bucal; limpiar y retirar cuidadosamente los restos alimenticios de dientes y férula evitando la retención de los mismos, lavados de colutorios de clorhexidina acuosa 0,12 \% para evitar la contaminación microbiana. 6,12

Al paciente se dio las siguientes recomendaciones: dieta blanda, evitar morder con los dientes afectados y ferulizados durante 4 semanas, en este periodo los alimentos se cortarían en fragmentos pequeños y se masticarían con los otros dientes ${ }^{14,15}$. Una semana después se retiraron los puntos de sutura. La férula se retiró al mes una vez comprobada la estabilidad del diente en su alvéolo.

Doce meses después del reimplante se toma la radiografía panorámica y se observa signos radiográficos de reabsorción ósea. ${ }^{10,13}$

Después del reimplante, se forma un coágulo entre las dos zonas del ligamento periodontal seccionado. La solución de continuidad generalmente se encuentra en la mitad del ligamento, pero puede ocurrir a nivel del cemento o en el hueso alveolar. Dos semanas después, la herida está cicatrizada y las fibras de colágeno se extienden desde el cemento hasta el hueso. En este momento se comienzan procesos de reabsorción a lo largo de la superficie radicular, pudiendo evolucionar a una nueva reparación con cemento dando lugar a una reabsorción superficial 0 a procesos de reabsorción inflamatoria 0 anquilosis. ${ }^{26}$

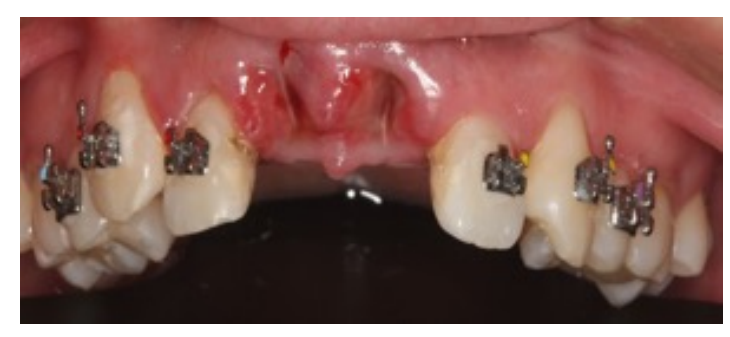

Figura 9.- Bondeado de braquets en las piezas vecinas

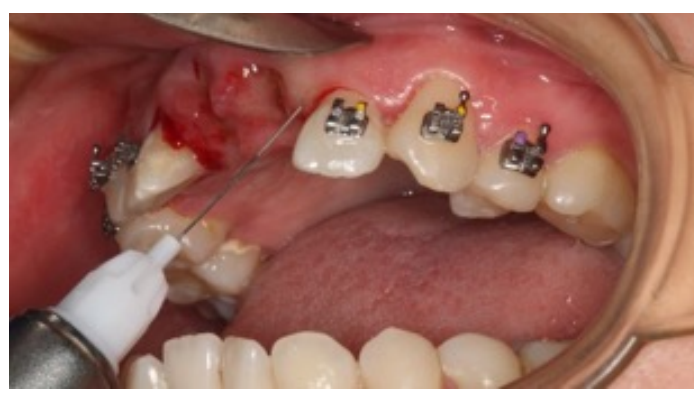

Figura 10.- Anestesia locorregional 


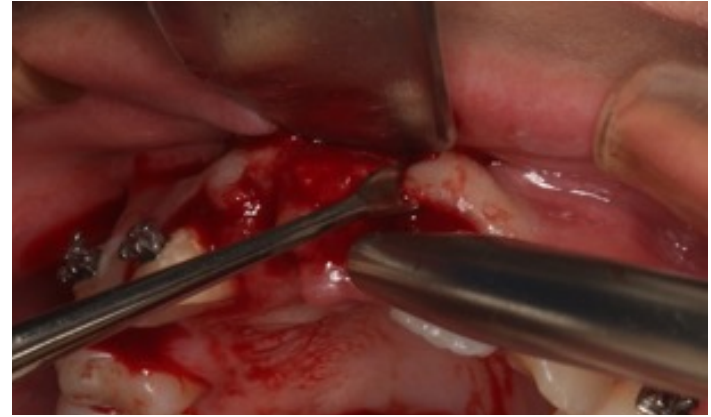

Figura 11.- Levantamiento de colgajo y curetaje

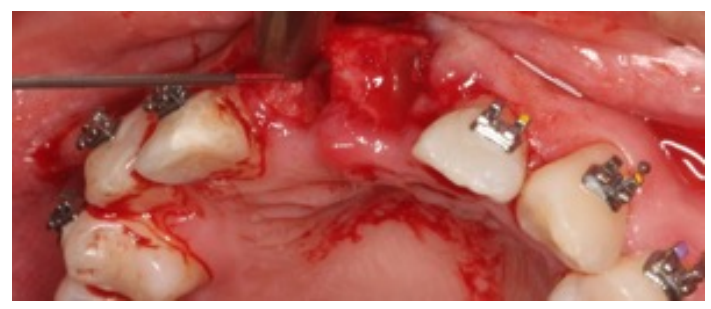

Figura 13.- Irrigación con suero fisiológico

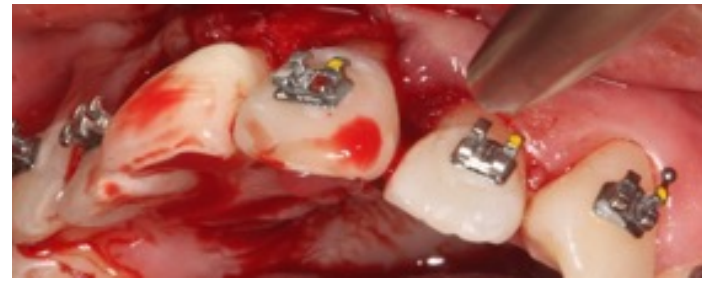

Figura 15.- Reimplantación de la pieza 2.1

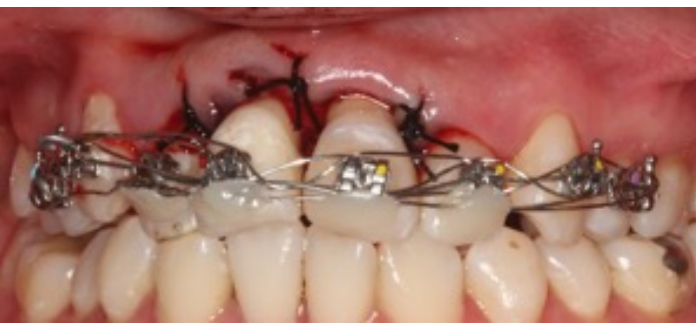

Figura 17.- Ligadura en 8 y bondeado con resina como férula

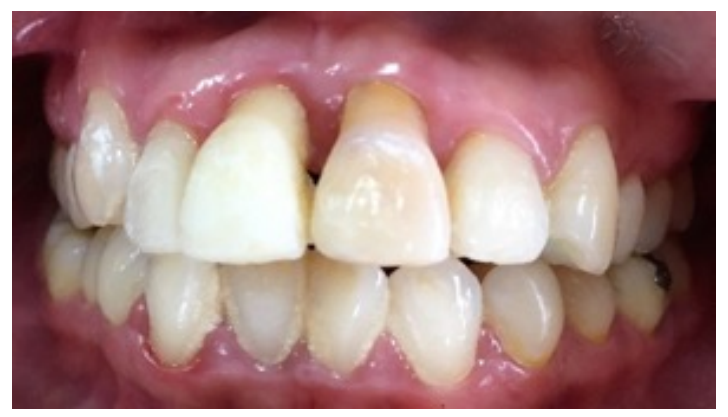

Figura 19.- Control clínico al año

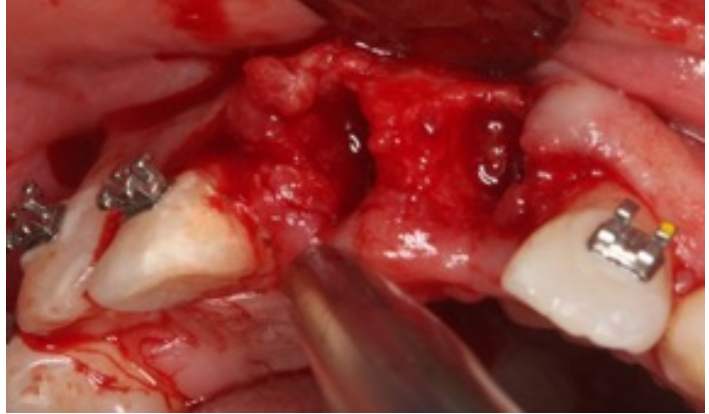

Figura 12.- Formación del lecho alveolar

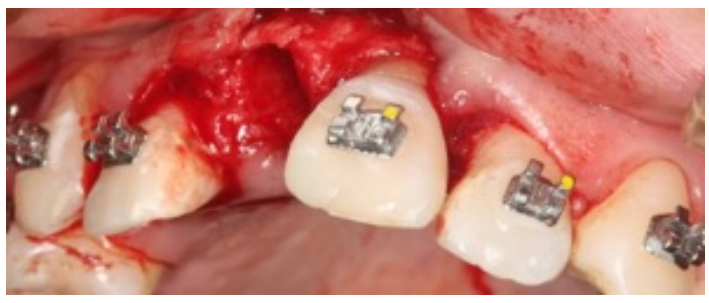

Figura 14.- Reimplantación de la pieza 1.1

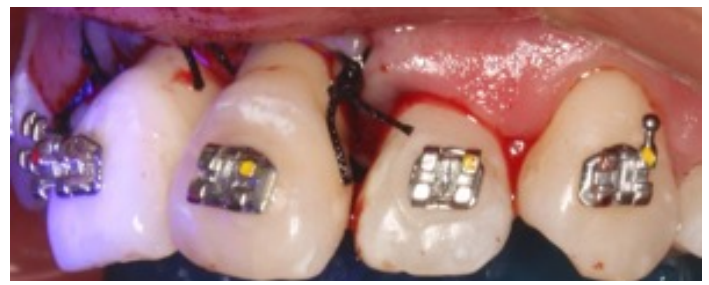

Figura 16.- Sutura

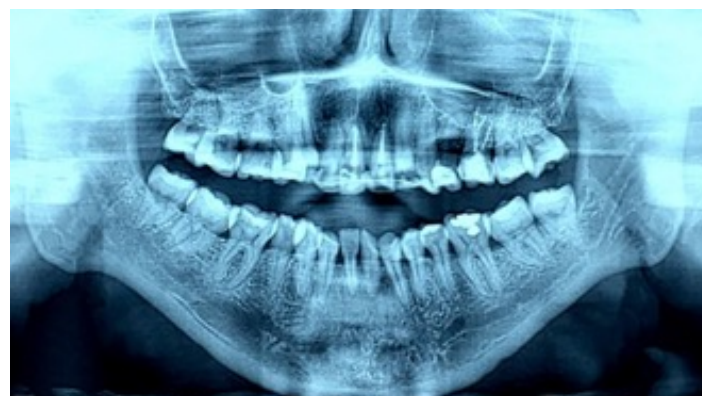

Figura 18.- Radiografía control al año 


\section{Discusión}

Los resultados de este procedimiento no fueron del todo satisfactorios luego de 1 año de haber sido realizado, presentando deficiencias en el aspecto estético y periodontal, aun así, el paciente conserva sus dientes a pesar de lo descrito por otros autores donde se indica que transcurridos periodos largos de tiempo después del trauma, presenta un mal pronóstico. ${ }^{17-21}$

Es importante mencionar que la edad es un factor predisponente ya que en edades tempranas se obtiene mejores resultados ${ }^{22,23}$ debido a que las características del hueso alveolar es más laxo, además de la respuesta inmunológica regenerativa y vascular ${ }^{24,18-19,25-26}$ en nuestro caso la paciente es adulto y con tratamiento tardío presentando pronósticos desfavorables y con desconocimiento de cómo proceder ante esta situación, 27,19,28 la decisión de realizar el reimplante dentario depende tanto del paciente como del profesional, en la bibliografía revisada no se encuentran casos registrados de reimplantes realizados con más de 72 horas de avulsionado el diente ${ }^{29}$ por lo que consideramos que el resultado obtenido está relacionado tanto con la edad como con el tiempo de espera para la reimplantación, aun así el paciente se siente satisfecho de haber podido mantener sus piezas dentarias en boca.

Con este resultado se puede optar posteriormente a realizar un tratamiento de rehabilitación menos complejo y con mejores resultados tanto estéticos como funcionales, manteniendo de esta manera el espacio, los tejidos óseos y mucosos del diente perdido, los mismos que se ven afectados el momento de la avulsión dental, hay que considerar que el objetivo es lograr prevenir la reabsorción ósea y la perdida de dimensión del alveolo ${ }^{30}$ a diferencia de lo que sucede al realizar un tratamiento definitivo con implantes dentales, ya que no se puede obtener un buen contorno alveolar y altura ósea, ocasionando un problema estético de difícil tratamiento. ${ }^{31}$

El mejor tratamiento es la reimplantación del propio diente del paciente. ${ }^{32-33}$

Acompañado con lo que menciona Andreasen, acerca de que la intervención antibiótica inicial es un factor significativo para controlar la infección de los tejidos blandos. ya que los dientes contaminados fueron casi tres veces más propensos de sufrir resorción que los dientes no contaminados. ${ }^{34,35}$

En el presente trabajo, enfatiza la importancia de un tratamiento inmediato y el seguimiento de pautas clínicas protocolizadas basadas en la evidencia son claves en el éxito del tratamiento de los dientes avulsionados. ${ }^{36}$ 


\section{Referencias Bibliográficas:}

1. Cortés GM, Hernández PJ, Valenzuela EE. Tratamiento del diente avulsionado: Caso clínico, seguimiento a 5 años. Rev Odont Mex [Internet]. 2010 [citado 16 ene 2018]; 14(4):249-257. Disponible en: http://www.scielo.org.mx/pdf/rom/v14n4/1870-199Xrom-14-04-00249.pdf

2. Padilla R, Dorney B, Balikov S. Prevention of oral injuries. CDA J [Internet]. 1996 [citado 16 ene 2018]; 24(3): 30-36. Disponible en: https://www.ncbi.nlm.nih.gov/pubmed/9063191

3. Oulis CJ, Berdouses ED. Dental injuries of permanent teeth treated in private practice in Athens. Endod Dent Traumatol [Internet]. 1996 [citado 17 ene 2018]; 12(2): 60-65. Disponible en: https://www.ncbi.nlm.nih.gov/pubmed/9028198

4. Dewhurst SN, Mason S, Roberts GJ. Emergency treatment of orodental injuries: a review. Br J Oral Maxillof Surg [Internet]. 1998 [citado 17 ene 2018 ]; 36(3): 165-175. Disponible en: https://www.ncbi.nlm.nih.gov/pubmed/9678879

5. Casals GY, Montero del Castillo ME, González NG. Prevalencia de secuelas de traumatismos en dientes temporales en niños institucionalizados del municipio Playa. Rev Cub E [Internet]. 2011 [citado 17 ene 2018]; 48 (1): 14-21. Disponible en:http://scielo.sld.cu/scielo.php?script=sci_abstract\&pid=S0034-75072011000100004\&lng=es\&nrm=iso\&tlng=es

6. Ruiz de Gopegui-FJ. Incisivo central permanente avulsionado. Conducta y caso clínico. RCOE [Internet] 2003 [citado 18 ene 2018]; 8(4):429-437. Disponible en: http://scielo. isciii.es/pdf/rcoe/v8n4/429\%20incisivo.pdf

7. Zhao Y, Gong Y. Knowledge of emergency management of avulsed teeth: a survey of dentist in Beijing, China. Dental Traumatology. [Internet]. 2010 [citado 17 ene 2018]; 26(3): 281-284. Disponible en: http://onlinelibrary.wiley.com/wol1/doi/10.1111/j.16009657.2010.00877.x/full

8. Andreasen JO, Borum MK, Jacobsen HL, Andreasen FM. Replantation of 400 avulsed permanent incisors. 2. Factors related to pulpal healing. Endod Dent Traumatol [Internet]. 1995 [citado 18 ene 2018]; 11 (2): 59-68. Disponible en: https://www.ncbi.nlm.nih.gov/ pubmed/7641620

9. Barrett EJ, Kenny DJ. Survival of avulsed permanent maxillary incisors in children following delayed replantation. Endod Dent Traumatol [Internet].1997 [citado 18 ene 2018];13(6):269-275. Disponible en: https://www.ncbi.nlm.nih.gov/pubmed/9558508

10. Malhotra N, Cyriac R, Acharya S. Clinical implications of storage media in dentistry: a review. Endo. EPT [Internet]. 2010 [citado 22 ene 2018]; 4(3) 179-188. Disponible en: http:// quintpub.com/journals/endo/abstract.php?iss2_id=906\&article_id=10363\&article=3\&title=clinical\%20implications \%20of\%20storage \%20media\%20in \%20dentistry:\%20 a\%20review\#.

11. Flores MT, Cols. Guidelines for the management of traumatic dental injuries. II. Avulsion of permanent teeth. Dental Traumatology [Internet]. 2006 [citado 22 ene 2018]; 14(1); 110-118. Disponible en: https://www.ncbi.nlm.nih.gov/pubmed/17511833

12. Bae JH, Choi YH, Cho BH, Kim YK, Kim SG.Autotransplantation of teeth with complete root formation: a case series. J Endod [Internet]. 2010 [citado 22 ene 2018]; 36(8):1422- 
14226. Disponible en: https://www.ncbi.nlm.nih.gov/pubmed/20647110

13. Pfadt E, Carlson DS. Avulsión dental. Dialnet [Internet]. 2012 [citado 22 ene 2018]; 30(10):7. Disponible en: https://dialnet.unirioja.es/servlet/articulo?codigo=4137575

14. Rosenblatt A. The best treatment for avulsed permanent teeth. Evid Based Dent. [Internet]. 2010 [citado 22 ene 2018];11(2):42-3. Disponible en: https://www.researchgate. net/publication/44799281_The_best_treatment_for_avulsed_permanent_teeth

15. Trope M. Avulsion of permanent teeth: theory to practice. Dent Traumatol. [Internet]. 2011 [citado 22 ene 2018];27(4):281-294. Disponible en: https://pdfs. semanticscholar.org/8131/ccb3644bdd26950f8d0e884ac53762971315.pdf?_ ga=2.193450477.1570266061.1521132454-1294684429.1521132454

16. Mori GG, Nunes DC, Castilho LR, de Moraes IG, Poi WR.Propolis as storage media for avulsed teeth: microscopic and morphometric analysis in rats. Dent Traumatol. . [Internet] 2010 [citado 22 ene 2018]; 26(1):80-85.disponible en: https://www.ncbi.nlm.nih.gov/ pubmed/20089064

17. Watanabe Y. Long-term observation of autotransplanted teeth with complete root formation in orthodontic patients. Am J Orthod Dentofacial Orthop. [Internet] 2010 [citado 22 ene 2018];138(6):720-726. Disponible en: https://www.ncbi.nlm.nih.gov/pub$\operatorname{med} / 21130330$

18. García MI, Palma J, Espinozaii E. Tratamiento del diente avulsionado: Casoclínico, seguimiento a 5 años. Revista Odontológica Mexicana. 2010; 14(4):249-257.

19. Roig A. Análisis Morfométrico del Número de Odontoblastos en Recubrimientos Directos con Hidróxido de Calcio y Propóleos en Canes. Int. J. Morphol. 2011;29(3):799-805.

20. Petrovic B. Factors related to treatment and outcomes of avulsed teeth. Dent Traumatol. 2010; 26(1):52-59.

21. Wang Y. The Effect of Cultured Autologous Periodontal Ligament Cells on the Healing of Delayed Autotransplanted Dog's Teeth. J Endod. 2010; 36(2):264-267.

22. Andersson L. International Association of Dental Traumatology guidelines for the management of traumatic dental injuries: 2. Avulsion of permanent teeth. Dent Traumatol. $2012 ; 28(2): 88-96$.

23. Park JH, Tai K, Hayashi, D. Tooth autotransplantation as a treatment option: A review. J Clin Pediatr Dent. 2010; 35(2):129-135.

24. Tolentino LS. Incisivo permanente avulsionado-reimplante após dois dias do trauma: relato de um caso. Revista odontológica Universidad de la Ciudad de Sao Paulo. 2010; 22(1):70-7.

25. Hecova H, Tzigkounakis V, Merglova V, Netolicky J.A retrospective study of 889 injured permanent teeth. Dent Traumatol. 2010; 26(6):466-475.

26. Rosenblatt A. The best treatment for avulsed permanent teeth. Evid Based Dent. 2010; $11(2): 42-43$.

27. Arroyo S,Martínez J,Brau E, Berástegui E. Avulsión y reimplante en paciente joven: 15 años de evolución. REDOE. 2014; 15: 13-31 
28. Savi A, Turillazzi O, Cocconi R, Bonanini M, Pizzi S, Manfredi M. Central incisor loss after delayed replantation following avulsion: a contemporary restorative and adjunctive orthodontic management approach. Dent Traumatol. 2012; 28: 161-165

29. Andreasen J0, Andreasen FM, Skeie A, Hjørting-Hansen E,Schwartz O. Effect of treatment delay upon pulp and periodontal healing of traumatic dental injuries -a review article. Dental Traumatol 2002; 18: 116-128.

30. Gómez PC, Linares IA, M.D. HuertaS, Mendoza MA. Protocolo de actuación y tratamiento adecuado de las complicaciones para el éxito del reimplante tras una avulsión dental. Caso clínico. Odontología Pediátrica. 2014; 22(3): 183-194

31. Roig A. Análisis Morfométrico del Número de Odontoblastos en Recubrimientos Directos con Hidróxido de Calcio y Propóleos en Canes. Int. J. Morphol. 2011;29(3):799-805.

32. Watanabe Y, Mohri, M Takeyama, M Yamaki Long-term observation of autotransplanted teeth with complete root formation in orthodontic patients. Am J Orthod Dentofacial Orthop. 2010;138(6):720-726.

33. Trope M. Avulsion of permanent teeth: theory to practice. Dent Traumatol. 2011;27(4):281294.

34. Mori GG. Propolis as storage media for avulsed teeth: microscopic and morphometric analysis in rats. Dent Traumatol. 2010;26(1):80-85.

35. HuertaS, Mendoza MA. Protocolo de actuación y tratamiento adecuado de las complicaciones para el éxito del reimplante tras una avulsión dental. Caso clínico. Odontol Pediátr. 2014; 22(3): 183-194

36. Morales BB, Pinos NP, Cordero LM. Dental fragments collage adhesion. Rev Kill.2017; 1(3): 7-14.

Recibido: 14 Septiembre 2020

Aceptado: 17 Diciembre 2020 